way; the catgut, also failing us when most required, and at no time acting as efficiently, is also inferior.

More than a year's experience of the hair-drain in all classes of surgical cases will, I think, justify me in speaking so decidedly in ita favour.

Your obedient servant, Lewis W. Marshall, M.D.,

Surgeon to Children's Hospital, late Resident Surgeon January $22 \mathrm{nd}, 1878$ to the General Hospital, Nottingham.

\section{POISONING PER VAGINAM.}

I"o tho Editos" of THE LANCET.

SIR, - I have thought it worth while to record in the columns of TEL LANCET the particulars of a case which occurred to me, now fifteen years ago.

A young rnarried lady, mother of two children, went to London to place herself under the care of an eminent obstetric physician, now some years deceased, for the cure of some uterine complaints, real or imaginary, most probably the latter. On leaving London, she received a prescription for a vaginal injection, which was not used until after she had been a few days at home. The result was an immediate accession of intense pain in the vagina and abdomen, with a copious discharge of thin watery mucus, followed, in the conrse of a few hours, by swelling of the gums and salivary glands, with profuse ptyalism. Her life was for several days in considerable danger, but she eventually recovered gradually.

The cause of the symptoms was not at first quite obvious, the whole of the injection ( $40 z_{.}$) having been used, and the prescription not forthcoming. When a copy was obtained next day from London, the cause and course of events became clear. The prescriber, meaning to order calomel and limewater, had by an unfortunate slip of the pen, written hydrarg. hichlorid., Bij, with aq. calcis, Jiv.

I think cases of vaginal poisoning are by no means common, though I have had the opportunity of knowing that the in cantious use of bichloride of mercury externally may prove fatal. On the other hand, Orfila, Beck, and others relate cases of fatal poisoning by arsenic feloniously introduced into the vagina. In any case the rapidity with which absorption takes place from that mucous surface is well worthy of notice, and is calculated to inspire caution in the use of potent agents throwshth that chanel.

I am, Sir, yours faithfully,

Sath, Jan. St: 23.8

R. T. GORE.

\section{COLONIAL MEDICAL DEGREES.}

\section{To the Editor of THE LANCET.}

SIR,-In IHE LANCET of June 2nd, page 815, it is stated, "the Colonies revexamine men holding British qualifications before they are admitted to practice in those outlying provinces," \&o.

I beg to state this is not the case here, nor do I know of any colony in which such re-examinations are practised. Medical men arriving in this colony are simply required to snbmit their testimonials for registration, and afford such proof as may be nossible of their identity with the individuals named in the document.

May I take this opportunity of inquiring if registration, as lately acreed to by the (Teneral Medical Council, confers on holders of colonial degrees or diplomas any substantial benefit, such, for instance, as the right to practise in Great Britain, or in the empire generally? I ask this because in the Royal Letters Patent, issued to the Melbourne University, March 14th, 1859 (the University having been incorporated about six years previously), I read as follows:"We ..... do by virtue of our Prerogative Royal, and of our especial grace and certin knowledge, and mere motion by these presents, for us, our heirs and successors, will, grant and declare that the degreas of Bachelor of Arts, Master of Arts, Bachelor of Medioine, Doetor of MTedicine, Bachelor of Laws, Doctor of Laws, Buehelor of Music, and Doctor of Music, already granted or conferred, or hereafter to be granted or conferred, by the said University of Melbourne, shall be recognised.as academic distinctions and rewards of merit, and be entitled to rank, precedence, and consideration in our nited Kingdom, and in our Colonies and possessions throughout the world, as fully as if the said degrees had been granted by any University in our said United Kingdom," \&tc.
The words, "as fully," indicate, I think, the perfect equality in all professional rights of the Melbourne with the 13ritish graduates, and, of all rights, that of practising their profession throughout the empire generally is the most im. portant and valuable.

I remain, Sir, yours obediently, J. W. AGNEW, M.D.,

Hon. Sec., Court of Medical Examiners.

Hobart Town, Tasmania, Nov. 9th, 1877.

** We the more readily insert our correspondent's letter, as undoubtedly he is right as to the colonies not re-examining those who hold British qualifications. The Medical Act empowers such persons to practise in all parts of Her Majesty's dominions. An amending Act, in 1868, gave colo. nial Legislatures the power to make laws enforcing registra. tion, within their respective jurisdictions, of persons registered under the Medical Act. It provided, however, that persons already registered under the Medical Acts should be entitled to be registered under the Colonial Act on simple payment of fees. By some inadvertence we represented the colo. nies as re-examining the holders of British qualifications, Holders of colonial degrees are not at present entitled to practise in England. In any amendment of the Medical Act it is probable that the holders of the best colonial degrees will be recognised.-ED. $\mathrm{L}$.

\section{TREES IN TOWNS.}

\section{To the Editor of THE LANCET.}

SiR,-In a recent number of your journal you allude to the fact that persistent efforts are being made to plant trees in streets wherever practicable. You are apparently much in favour of this movement, and state that the hygienic value of trees in towns must be great. I have always been of opinion that the freer and more unobstructed the avenues for fresh air, nature's grand deodorizer, are the better; especially in towns, where there is al dense population and vile scents and odours, fresh air is most needed, and the stopping up of the free thoroughfare by dense and dark foliage will be most pernicious. It will prevent the foul air being swept away and our close neighbourhoods purified, while by personal and practical experience $I$ know that disease is increased by close humid atmospheres. If you will kindly point out in an early number where $I$ am in error $I$ shall be obliged, otherwise I do hope that you will, as a faithful guardian of the public health, do what you can to prevent anything which will, if I am correct, be so hurtful to oul populations.

I can, I hope, appreciate beauty in nature, and am glad that now by means of parks it is happily within reach of al of us; I only protest against a deadly development of modem ideas of beauty.

I am, Sir, your obedient servant,

Westminster, Jun. 22nd, 1878

William C. STREeT.

\section{ARSENICAL WALL-PAPERS.}

To the Editor of THE LANCET.

SIR,-Permit me to call attention once more in your columns to this subject. I need not say a single word as to the danger of such poisonous ornaments, for you have often done that, but I wish to point out that the bright greens are not the only tints to be avoided. Any papers which con tain a sea-green pattern, or even an opal white ground, may, according to the present custom of paper stainers, be s0 heavily coloured with arsenic as to be dangerous.

I have just analysed every sample of paper from a tellroomed house, and although no single paper could, by any stretch of imagination, be called green, two samples are badly arsenical, and three more contain some arsenic-five bad samples from ten rooms.

It seems to me that colouring paper with poisonous colours should be made a criminal offence. The harm inflicted is worse because, in many cases, the source is unsuspected. Yours truly,

$$
\text { G. J. WIGNER, F.C.S. }
$$

Laboratory, Great Tower-street, Jan. 17th, 1878 . 